\title{
Clinically-Based Determination of Safe DNAemia Cutoff Levels for Preemptive Therapy or Human Cytomegalovirus Infections in Solid Organ and Hematopoietic Stem Cell Transplant Recipients
}

\author{
Daniele Lilleri, Fausto Baldanti, Marta Gatti, Francesca Rovida, Luca Dossena, \\ Simona De Grazia, Maria Torsellini, and Giuseppe Gerna* \\ Servizio di Virologia, IRCCS Policlinico San Matteo, Pavia, Italy
}

Transplantation Centers using human cytomegalovirus (HCMV) antigenemia-based preemptive therapy will need to replace in the near future the antigenemia assay with a more standardized and automatable assay, such as a molecular assay quantifying HCMV DNA in blood (DNAemia). Thus, in view of replacing antigenemia with clinically safe cutoff values, DNAemia levels corresponding to antigenemia cutoffs guiding HCMV preemptive therapy were determined retrospectively in solid organ and hematopoietic stem cell transplant recipients (HSCTR) using an "in-house" quantitative PCR (QPCR) method. Since preemptive therapy had prevented appearance of HCMV disease in all patients tested, DNA cutoffs determined retrospectively had to be considered as safe clinically as antigenemia cutoffs used prospectively. However, in solid organ transplant recipients (SOTR), initiating preemptive therapy upon an antigenemia cutoff of 100 pp65-positive leukocytes, a DNAemia cutoff of 300,000 copies $/ \mathrm{ml}$ blood had positive and negative predictive values of $>90 \%$, indicating that a DNAemia cutoff could achieve, in terms of prevention of HCMV disease, the same clinical results as the antigenemia cutoff. In HSCTR, initiating preemptive therapy upon first antigenemia positivity, a DNAemia cutoff of 10,000 copies $/ \mathrm{ml}$ blood had a positive predictive value of $>90 \%$, indicating that the great majority of patients treated under the antigenemia guidance would have been treated also using this DNA cutoff. On the other hand, the negative predictive value of $28.6 \%$ indicated that two out of three HSCTR had been treated under the antigenemia guidance having the same levels of viral DNA as the untreated patients. The data suggest that a quantitative cutoff could be adopted as a guiding criterion for preemptive therapy also in HSCTR. Regression analysis allowed to determine the
DNAemia (corresponding to QPCR) cutoff values for two commercial assays tested both in solid organ and HSCTR. Retrospective DNAemia cutoff values will be verified for safety in prospective trials. J. Med. Virol. 73:412-419, 2004.

() 2004 Wiley-Liss, Inc.

KEY WORDS: HCMV antigenemia; quantitative PCR; positive predictive value; negative predictive value; Digene Hybrid Capture; Amplicor CMV Monitor

\section{INTRODUCTION}

Preemptive therapy is an effective approach to control human cytomegalovirus (HCMV) infections in transplant recipients, based on the administration of antiviral drugs upon detection of HCMV in blood, in view of treating only patients undergoing active viral infection and, thus, at risk of developing overt HCMV disease [Einsele et al., 1995; Boeckh et al., 1996; Egan et al., 1998; Ljungman et al., 1998; Kusne et al., 1999]. Preemptive therapy is currently started upon reaching predetermined levels of viral load in solid organ transplant recipients (SOTR), whereas in hematopoietic

Grant sponsor: Ministero della Salute, Ricerca Corrente IRCCS Policlinico San Matteo; Grant number: 80541; Grant sponsor: Istituto Superiore di Sanità, Progetto Multidisciplinare sulla Terapia delle Malattie da Virus; Grant number: 0AG/F16; Grant sponsor: Ministero dell'Istruzione, Università e Ricerca Scientifica, Consiglio Nazionale delle Ricerche; Grant number: 01.00696.PF49.

*Correspondence to: Giuseppe Gerna, Servizio di Virologia, IRCCS Policlinico San Matteo, via Taramelli 5, 27100 Pavia, Italy.

E-mail: g.gerna@smatteo.pv.it

Accepted 2 March 2004

DOI 10.1002/jmv.20107

Published online in Wiley InterScience

(www.interscience.wiley.com) 
stem cell transplant recipients (HSCTR) treatment is started upon the first appearance of virus in blood [Einsele et al., 1991; Gerna et al., 1995; Grossi et al., 1995; Boeckh and Boivin, 1998; Razonable et al., 2002b].

One of the diagnostic assays used for preemptive therapy has been antigenemia [Van der Bij et al., 1988; Revello et al., 1989; Boeckh et al., 1992; Locatelli et al., 1994], which, however, is not a direct marker of viral replication, being based upon detection in peripheral blood leukocytes of a viral protein (pp65) synthesized in large excess in endothelial cells, and then transferred to leukocytes [Britt and Vugler, 1987; Gerna et al., 2000b, 2003c]. In addition, antigenemia has been shown to increase in level during antiviral treatment either dissociated from a similar trend of viremia and DNA in blood (DNAemia) in solid organ transplanted patients with primary infection [Gerna et al., 1998b] and HSCTR [Boeckh et al., 1996; Gerna et al., 2003b] or associated with the rising viremia and DNAemia in hematopoietic stem cell transplanted patients with steroid-treated graft-versus-host disease [Nichols et al., 2001]. DNAemia, instead, appears to correlate better with the presence of infectious virus in blood and with clinical manifestations of viral infection [Gerna et al., 1998a,b, 2003a]. In addition, assays for DNAemia quantitation can be standardized more easily and automated than antigenemia.

For more than a decade, the preemptive therapy approach to the treatment of HCMV infections in transplant recipients at the University Hospital IRCCS Policlinico San Matteo, Pavia, Italy, has been based upon a cutoff of $100 \mathrm{pp} 65$-positive $/ 2 \times 10^{5}$ leukocytes in reactivated infections of SOTR, and upon the first confirmed antigenemia positivity in primary HCMV infections of SOTR as well as in HCMV infections of HSCTR [Gerna et al., 2003a,b]. This approach has been safe and has prevented consistently HCMV disease.

In this report, DNAemia levels present in patients belonging to either transplanted patient population at time of initiation of antigenemia-guided preemptive therapy were reassured retrospectively. DNAemia levels were determined by using an "in-house" quantitative PCR (QPCR) method. Subsequently, in order to match cutoff levels determined by the QPCR method to commercially available molecular systems, a subset of blood samples from transplanted patients assayed previously by QPCR were tested by two commercial assays. Then, regression analysis was used to extrapolate comparable DNA cutoffs between the "in-house" method and the two commercial molecular assays.

\section{MATERIALS AND METHODS}

\section{Patients}

Initially, QPCR DNA was quantified retrospectively in 35 SOTR with as many episodes of active HCMV infection, 11 of which reached the antigenemia cutoff level for treatment initiation (100 pp65-positive $/ 2 \times 10^{5}$ leukocytes), while the other 24 patients resolved the infection spontaneously [Gerna et al., 2003a]. In addi- tion, 56 HSCTR patients with as many episodes of HCMV infection treated upon the first confirmed antigenemia and 19 HSCTR patients with as many episodes of self-resolving (antigenemia not confirmed at the following test) HCMV infection were evaluated retrospectively for DNAemia levels [Gerna et al., 2003b]. Then, sequential blood samples from 19 SOTR (13 heart and 6 lung transplant recipients) and 23 HSCTR were evaluated in parallel for HCMV DNAemia quantitation by both QPCR and two commercial assays.

\section{Viral DNA Assays}

HCMV DNA was quantified by the "in-house" method of QPCR [Gerna et al., 1994, 1998a] and the following two commercial assays: the Digene Hybrid Capture ${ }^{\mathbb{R}}$ System CMV DNA version 2.0 (HCS, Abbott Laboratories, Abbott Park, IL) and the COBAS ${ }^{\circledR}$ Amplicor CMV Monitor $^{\mathrm{TM}}$ Test (Amplicor, Roche Diagnostic System, Pleasanton, CA). HCMV DNA was determined on whole blood by QPCR, hybrid capture system (HCS) and Amplicor-whole blood. In addition, HCMV DNA was determined on plasma by Amplicor-plasma. HCS and Amplicor-plasma were performed according to manufacturer's instructions, and quantitative results were referred to $1.0 \mathrm{ml}$ whole blood or plasma, respectively. For QPCR and Amplicor-whole blood, nucleic acids were isolated from $100 \mu \mathrm{l}$ whole blood using NucliSens Isolation Kit (bioMerieux, Boxtel, The Netherlands). DNA quantitation for QPCR was performed on 1/10 of the elution product. Amplicor was adapted to whole blood by diluting 1:8 with dilution buffer (as in the plasma assay) the same nucleic acid extract. Internal standard was then added and $50 \mu \mathrm{l}$ of the solution (corresponding to $12.5 \mu \mathrm{l}$ whole blood) was submitted to amplification. Then, the same procedure used for Amplicor-plasma was followed. Uniformity of results was achieved by expressing QPCR and Amplicor-whole blood final results as HCMV DNA copies/ml whole blood. Positive QPCR values $<1,000$ copies/ml were assigned an arbitrary value of 500 copies $/ \mathrm{ml}$.

\section{Statistical Analysis}

Chi-square test was used to compare sensitivities of the different assays, while Pearson's correlation between QPCR and the two commercial assays was calculated. Regression curves were drawn to compare QPCR cutoff values with those of the two commercial assays.

\section{RESULTS}

\section{Retrospective Determination of DNAemia Cutoff Levels Upon the Start of Preemptive Therapy}

All transplanted patients undergoing antigenemiabased preemptive therapy and examined retrospectively for HCMV DNA had a favorable outcome of the HCMV infection without the occurrence of HCMV disease. Therefore, the proposal of DNAemia cutoff levels, 
to be verified in prospective trials, was based on the clinical safety of antigenemia-guided cutoffs, and DNA cutoffs were selected to achieve the highest levels of sensitivity, specificity, positive and negative predictive values for detection of patients requiring treatment with respect to antigenemia-based and clinically validated cutoffs.

Retrospective analysis of DNAemia levels determined by QPCR in 35 SOTR at the time of initiation of preemptive therapy showed that more than $90 \%$ of patients treated on the basis of antigenemia had DNA levels above a cutoff of 300,000 copies $/ \mathrm{ml}$ whole blood (10/ 11 patients, sensitivity $90.9 \%$ ), while more than $90 \%$ of untreated patients had DNA levels below this cutoff (23/ 24 patients, specificity $95.8 \%$ ). This means that over $90 \%$ of either treated or untreated patients would have been managed by using DNAemia exactly as by using the antigenemia cutoff with respect to preemptive therapy. As shown in Figure 1A, individual DNA peak values detected in patients treated on the basis of antigenemia at the time when decision to treat was made were included in the range of 176,000-2,260,000 (median $1,000,000) \mathrm{copies} / \mathrm{ml}$, whereas those of untreated patients ranged from $<1,000$ to 366,200 (median 35,350) copies/ml. Thus, a cutoff level of 300,000 HCMV DNA copies/ml whole blood had a positive predictive value of 90.9\% (10/11 patients) and a negative predictive value of 95.8\% (23/24 patients) with respect to SOTR requiring initiation of antigenemia-based preemptive therapy. This cutoff appears worth verifying in prospective trials.

On the other hand, among HSCTR tested retrospectively at the time of preemptive therapy initiated upon first antigenemia positivity, 11/56 patients reached DNAemia levels which were above a cutoff of 10,000 DNA copies/ml whole blood (sensitivity 19.6\%), while 18/19 untreated patients, spontaneously clearing the infection, had DNAemia levels below this cutoff (specificity $94.7 \%$ ). This means that an arbitrary cutoff of 10,000 DNA copies/ml blood would have excluded from treatment more than $90 \%$ of patients untreated on the basis of antigenemia. Meanwhile, the same cutoff would have induced start of treatment in about only $20 \%$ of patients actually treated under the antigenemia guidance, thus avoiding or delaying treatment of the remaining patients. As shown in Figure 1B, individual DNA peak values relevant to HSCTR treated on the basis of first confirmed positive antigenemia were included in the range of $<1,000-99,400$ (median 1,750) HCMV DNA copies/ml, whereas those of patients spontaneously clearing the infection in the absence of

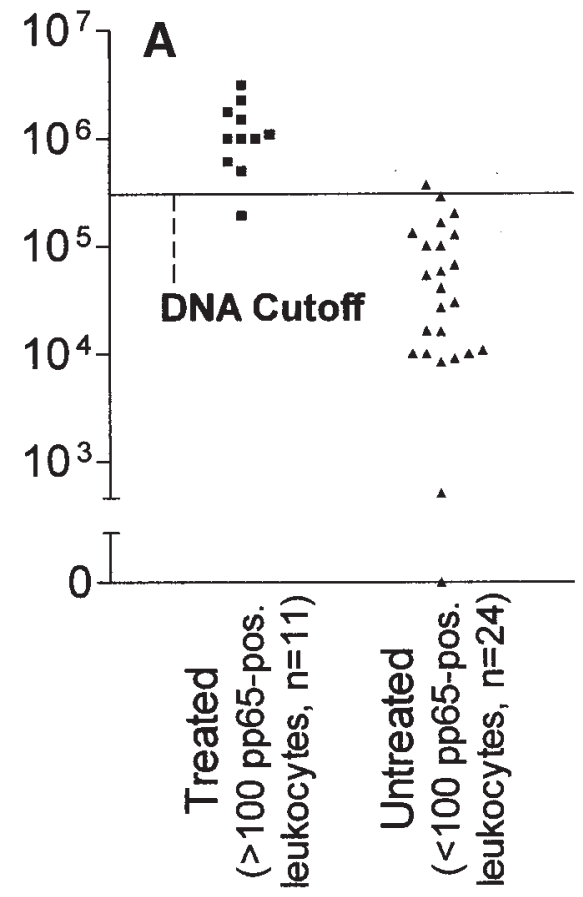

\section{Solid-organ transplant recipients}

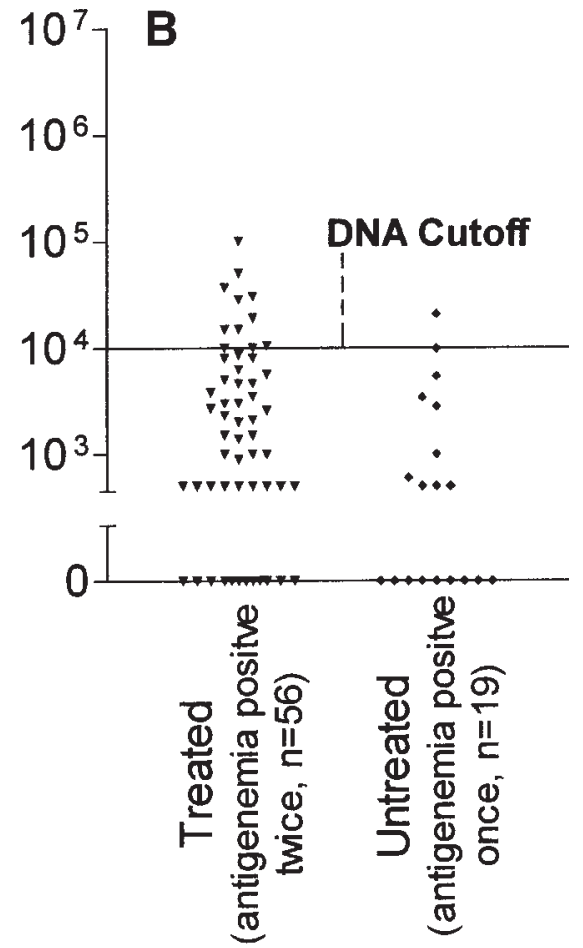

Hematopoietic stem cell transplant recipients

Fig. 1. Peak DNAemia levels as determined by quantitative PCR (QPCR) in solid organ transplant recipients (SOTR) and hematopoietic stem cell transplant recipients (HSCTR) either at the time when antigenemia-based preemptive treatment was decided (treated), or following selection from serial results in the absence of treatment (untreated). Cutoff DNA lines were extrapolated to select maximum levels of positive and negative predictive values with respect to antigenemia-guided preemptive therapy. 
treatment ranged from $<1,000$ to 20,800 (median $<1,000$ ) copies/ml. Thus, a cutoff level of 10,000 HCMV DNA copies $/ \mathrm{ml}$ whole blood showed a positive predictive value of $91.7 \%$ (11/12 patients) and a negative predictive value of $28.6 \%$ (18/63 patients) with respect to HSCTR requiring preemptive therapy on the basis of first confirmed antigenemia positivity. This data suggest that in HSCTR the use of a quantitative (rather than a qualitative) approach to preemptive therapy could avoid unnecessary treatment of a fair aliquot of patients, thus increasing the negative predictive value without changing the positive predictive value with respect to qualitative antigenemia.

\section{Correlation of QPCR and Commercial Assays}

A group of samples from both transplanted patient populations were tested for DNA both by QPCR and the two commercial assays to collate viral DNA quantitation obtained with different molecular methods and to define cutoff values of commercial assays corresponding to those previously determined by QPCR. On the whole, 585 samples were examined in parallel by QPCR and HCS, 558 by QPCR and Amplicor-whole blood and 240 by QPCR and Amplicor-plasma (Table I). QPCR was not significantly more sensitive than $\operatorname{HCS}(P>0.05)$, detecting HCMV DNA in 150/585 (25.6\%) versus $125 / 585$ (21.4\%) blood samples examined. On the contrary, QPCR showed higher sensitivity than Amplicor-whole blood $(P<0.01)$, detecting HCMV DNA in $183 / 558$ $(32.8 \%)$ versus $109 / 558$ (19.5\%) samples, and also higher sensitivity than Amplicor-plasma, detecting HCMV in $137 / 240(57.1 \%)$ samples tested versus $101 / 240(42.1 \%)$ $(P<0.01)$.

As shown in Figure 2, the correlation between HCS and QPCR was significant but markedly lower $(P<0.01$, $r=0.59)$ than that found between QPCR and Amplicorwhole blood ( $P<0.01, r=0.91)$. In addition, the correlation between Amplicor-plasma and QPCR on whole blood was significant but lower $(P<0.01, r=0.52)$. Regression curves were calculated to match QPCR DNAemia cutoff values retrospectively determined with those determined by using the two commercial assays. On this basis, by using a QPCR cutoff of 300,000 viral DNA copies/ml, the following DNAemia cutoff values
(95\% CI) of commercial assays could be established for SOTR: 117,169 (103,340-130,998) DNA copies/1.0 ml whole blood for HCS, 168,100 (160,600-175,700) DNA copies/ml whole blood for Amplicor-whole blood or 13,763 (10,750-17,016) DNA copies/1.0 ml plasma for Amplicor-plasma, with the Amplicor-whole blood assay showing the highest correlation with QPCR. For HSCTR, by using a QPCR cutoff of 10,000 copies/ml, cutoffs were lower by about one $\log _{10}$, or slightly more, for the two commercial assays with respect to SOTR.

\section{DISCUSSION}

The request for virological monitoring of HCMV infections in transplanted patients is increasing continuously in parallel with the increasing number of transplantations performed at different transplantation centers. In this respect, standardized protocols for HCMV infection surveillance and treatment as well as automatable diagnostic assays are needed. In the last decade, the antigenemia assay has been adopted as the test of choice for monitoring HCMV infections in several transplantation Centers in Italy and other European countries. However, antigenemia is time-consuming and requires a specific expertise. In addition, it does not allow processing of a high number of specimens per day. Hence, the need for developing standardized and automated assays. At the moment, quantification of HCMV DNAemia appears to be the best approach, among molecular tests, for monitoring HCMV infections. In fact, it reflects directly virus replication and may provide cutoff DNA levels for discriminating selfclearing infections from infections at risk of developing HCMV disease and, thus, requiring antiviral treatment [Emery et al., 2000; Gerna et al., 2003a,b]. In this respect, many Centers have chosen in the past to use PCR instead of antigenemia [Einsele et al., 1995; Paya et al., 2002]. However, safe cutoff values determined clinically in patients in whom HCMV disease was prevented, remain to be established.

In order to select clinically safe DNA cutoff levels to be verified in prospective trials, HCMV DNA levels present in blood of transplant recipients at time of initiation of antigenemia-based preemptive therapy, were tested and compared with peak values found in patients with

TABLE I. Human Cytomegalovirus (HCMV) DNA Detection in Blood Samples From Transplanted Patients, as Detected by Different Assays

\begin{tabular}{|c|c|c|c|c|}
\hline \multirow[b]{2}{*}{ Commercial assay } & \multirow[b]{2}{*}{ Result } & \multicolumn{2}{|c|}{ No. (\%) blood samples detected by $\mathrm{QPCR}^{\mathrm{a}}$} & \multirow[b]{2}{*}{$P^{*}$} \\
\hline & & Positive & Negative & \\
\hline $\mathrm{HCS}^{\mathrm{b}}(\mathrm{n}=585)$ & $\begin{array}{l}\text { Positive } \\
\text { Negative }\end{array}$ & $\begin{array}{c}104(17.8) \\
46(7.8)\end{array}$ & $\begin{array}{c}21(3.6) \\
414(70.8)\end{array}$ & $>0.05$ \\
\hline Amplicor-whole blood $(\mathrm{n}=558)$ & $\begin{array}{l}\text { Positive } \\
\text { Negative }\end{array}$ & $\begin{array}{r}101(18.1) \\
82(14.7)\end{array}$ & $\begin{aligned} 8 & (1.4) \\
367 & (65.8)\end{aligned}$ & $<0.01$ \\
\hline Amplicor-plasma $(\mathrm{n}=240)$ & $\begin{array}{l}\text { Positive } \\
\text { Negative }\end{array}$ & $\begin{array}{l}92(38.3) \\
45(18.8)\end{array}$ & $\begin{array}{c}9(3.7) \\
94(39.2)\end{array}$ & $<0.01$ \\
\hline
\end{tabular}

*Chi-square test between QPCR and the different commercial assays.

${ }^{\mathrm{a}} \mathrm{QPCR}$, quantitative PCR.

${ }^{\mathrm{b}} \mathrm{HCS}$, Hybrid Capture System. 
A

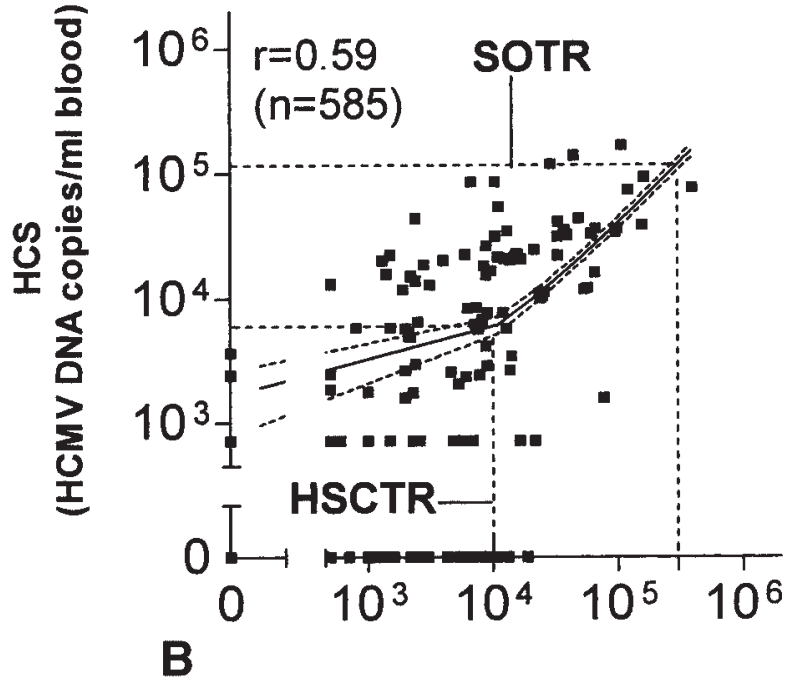

self-resolving infections. These values were determined by using the in-house QPCR method, which was subsequently compared with the two commercial systems tested. To reflect better the in vivo condition, in the last years HCMV DNA was quantitated on whole blood [Gerna et al., 2000a] instead of peripheral blood leukocytes [Gerna et al., 1994, 1998a]. More recently, whole blood has been reported as the optimal sample for HCMV DNA quantitative detection due to its higher sensitivity and higher yield of HCMV DNA [Razonable et al., 2002a].

The results described above indicate that HCS is as sensitive as QPCR in detecting HCMV in blood. However, from a quantitative standpoint, the correlation between the two assays did not appear to be very high. The best correlation was found between QPCR and Amplicor when both assays were performed on the same material (DNA isolated from whole blood), while the lower correlation between QPCR and Amplicor-plasma was likely to be related to the fact that HCMV in blood is mostly cell-associated.

Cutoff values determined for SOTR by the two commercial assays were approximated as follows: 100,000 copies/ml whole blood for HCS, 200,000 copies/ $\mathrm{ml}$ whole blood for Amplicor-whole blood, and 10,000 copies/ml plasma for Amplicor-plasma. These results are about ten times higher than those published recently on the comparison between levels of antigenemia and DNAemia using quantitative real time PCR [Li et al., 2003; Mengelle et al., 2003a,b]. However, in these reports, DNA cutoffs were extrapolated from correlation with antigenemia, without focusing on the patients' outcome, and, given the lack of standardization of antigenemia, cutoffs may not be comparable. In our study, the levels of viral DNAemia were those actually detected prior to the start of preemptive therapy, which prevented consistently HCMV disease and, thus, were verified as safe clinically. Cutoffs proposed by another group taking care of the patient clinical outcome were more similar to those calculated in the present study [Hadaya et al., 2003].

The results of this study suggest that a cutoff value might be adopted also for preemptive therapy of HSCTR. In this patient population, if treatment has to be started very early upon first appearance of virus in the blood (as determined by the current policy in most hematopoietic stem cell transplant recipients Centers), Amplicorwhole blood and Amplicor-plasma appear to be less sensitive than QPCR and HCS for early detection of HCMV. However, as shown in Figure 1, several patients undergoing antigenemia-guided preemptive therapy reached DNA levels $>10,000$ HCMV DNA copies/ml whole blood before initiation of treatment. Since none of

Fig. 2. Correlation of HCS (A), Amplicor-whole blood (B), and Amplicor-plasma (C) with the "in-house" QPCR. Regression curves with 95\% CI are shown. Retrospectively determined QPCR DNAemia cutoff values were interpolated on regression curves to determine the corresponding DNAemia cutoff values (dotted lines) of the two commercial assays tested for both SOTR and HSCTR. Correlation coefficient $(r)$ and number $(\mathrm{n})$ of blood samples tested are reported for each graph. 
these patients developed symptomatic disease, it is suggested that preemptive therapy may be delayed safely also in HSCTR until reaching a predetermined cutoff value, in order to avoid treatment of self-resolving infections. The interim analysis of an ongoing prospective trial, designed in our department to verify the clinical utility and safety of this DNAemia cutoff value in HSCTR, indicates that, using this approach, a fair number of patients will avoid unnecessary treatment due to self resolving HCMV infections (unpublished results).

\section{ACKNOWLEDGMENTS}

We thank Franco Locatelli for the helpful criticism, Lucia Chezzi and Cinzia Zanello for laboratory test performance and Linda D'Arrigo for revision of the English. We also thank Abbott and Roche for partially providing reagents.

\section{REFERENCES}

Boeckh M, Boivin G. 1998. Quantitation of cytomegalovirus: Methodologic aspects and clinical applications Clin Microbiol Rev 11:533554.

Boeckh M, Bowden RA, Goodrich JM, Pettinger M, Meyers JD. 1992. Cytomegalovirus antigen detection in peripheral blood leukocytes after allogeneic marrow transplantation. Blood 80:1358-1364.

Boeckh M, Gooley TA, Myerson D, Cunningham T, Schoch G, Bowden RA. 1996. Cytomegalovirus pp65 antigenemia-guided early treatment with ganciclovir versus ganciclovir at engraftment after allogeneic marrow transplantation: A randomized double-blind study. Blood 88:4063-4071.

Britt WJ, Vugler L. 1987. Structural and immunological characterization of the intracellular forms of an abundant 68,000 Mr human cytomegalovirus protein. J Gen Virol 68:1897-1907.

Egan JJ, Lomax J, Barber L, Lok SS, Martyszczuk R, Yonan N, Fox A, Deiraniya AK, Turner AJ, Woodcock AA. 1998. Preemptive treatment for the prevention of cytomegalovirus disease. Transplantation 65:747-752.

Einsele H, Ehringer G, Steidle M, Vallbracht A, Muller M, Schmidt H, Saal JG, Waller HD, Muller CA. 1991. Polymerase chain reaction to evaluate antiviral therapy for cytomegalovirus disease. Lancet 338:1170-1172.

Einsele H, Ehninger G, Hebart H, Wittkowski KM, Schuler U, Jahn G, Mackes P, Herter M, Klingebiel T, Loffler J. 1995. Polymerase chain reaction monitoring reduces the incidence of cytomegalovirus disease and the duration and side effects of antiviral therapy after bone marrow transplantation. Blood 86:2815-2820.

Emery VC, Sabin CA, Cope AV, Gor D, Hassan-Walker AF, Griffiths PD. 2000. Application of viral-load kinetics to identify patients who develop cytomegalovirus disease after transplantation. Lancet 355:2032-2036.

Gerna G, Baldanti F, Sarasini A, Furione M, Percivalle E, Revello MG, Zipeto D, Zella D. 1994. Effect of foscarnet induction treatment on quantitation of human cytomegalovirus (HCMV) DNA in peripheral blood polymorphonuclear leukocytes and aqueous humor of AIDS patients with HCMV retinitis. Antimicrob Agents Chemother 38:38-44.

Gerna G, Furione M, Baldanti F, Percivalle E, Comoli P, Locatelli F. 1995. Quantitation of human cytomegalovirus DNA in bone marrow transplant recipients. Br J Hematol 91:674-683.

Gerna G, Zavattoni M, Baldanti F, Sarasini A, Chezzi L, Grossi P, Revello M G. 1998a. Human cytomegalovirus (HCMV) leukoDNAemia correlates more closely with clinical symptoms than antigenemia and viremia in heart and heart-lung transplant recipients with primary HCMV infection. Transplantation 65:1378-1385.

Gerna G, Zavattoni M, Percivalle E, Grossi P, Torsellini M, Revello MG. 1998b. Rising levels of human cytomegalovirus (HCMV) antigenemia during initial antiviral treatment of solid organ transplant recipients with primary HCMV infection. J Clin Microbiol 36:11131116
Gerna G, Baldanti F, Lilleri D, Parea M, Alessandrino E, Pagani A Locatelli F, Middeldorp J, Revello MG. 2000a. Human cytomegalovirus immediate-early mRNA detection by nucleic acid sequencebased amplification as a new parameter for preemptive therapy in bone marrow transplant recipients. J Clin Microbiol 38:1845-1853.

Gerna G, Percivalle E, Baldanti F, Sozzani S, Lanzarini P, Genini E, Lilleri D, Revello MG. 2000b. Human cytomegalovirus replicates abortively in polymorphonuclear leukocytes after transfer from infected endothelial cells via transient microfusion events. J Virol 74:5629-5638.

Gerna G, Baldanti F, Lilleri D, Parea M, Torsellini M, Castiglioni B, Vitulo P, Pellegrini C, Vigano M, Grossi P, Revello MG. 2003a. Human cytomegalovirus pp67 mRNAemia versus pp65 antigenemia for guiding preemptive therapy in heart and lung transplant recipients: A prospective, randomized, controlled, open-label trial. Transplantation 75:1012-1019.

Gerna G, Lilleri D, Baldanti F, Torsellini M, Giorgiani G, Zecca M, De Stefano P, Middeldorp J, Locatelli F, Revello MG. 2003b. Human cytomegalovirus immediate early-mRNAemia vs. pp65-antigenemia for guiding pre-emptive therapy in children and young adults given hematopoietic stem cell transplantation: A prospective, randomized, open-label trial. Blood 101:5053-5060.

Gerna G, Sarasini A, Lilleri D, Percivalle E, Torsellini M, Baldanti F, Revello MG. 2003c. In vitro model for the study of the dissociation of increasing antigenemia and decreasing DNAemia and viremia during treatment of human cytomegalovirus infection with ganciclovir in transplant recipients. J Infect Dis 188:1639-1647.

Grossi P, Minoli L, Percivalle E, Irish W, Viganò M, Gerna G. 1995. Clinical and virological monitoring of human cytomegalovirus infection in 294 heart transplant recipients. Transplantation 59: 847-851.

Hadaya K, Wunderli W, Deffernez C, Martin PY, Mentha G, Binet I, Perrin L, Kaiser L. 2003. Monitoring of cytomegalovirus infection in solid-organ transplant recipients by an ultrasensitive plasma PCR assay. J Clin Microbiol 41:3757-3764.

Kusne S, Grossi P, Irish W, St George K, Rinaldo C, Rakela J, Fung J. 1999. Cytomegalovirus pp65 antigenemia monitoring as a guide for preemptive therapy: A cost effective strategy for prevention of cytomegalovirus disease in adult liver transplant recipients. Transplantation 68:1125-1131.

Li H, Dummer JS, Estes WR, Meng S, Wright PF, Tang YW. 2003 Measurement of human cytomegalovirus loads by quantitative real-time PCR for monitoring clinical intervention in transplant recipients. J Clin Microbiol 41:187-191.

Ljungman P, Aschan J, Lewensohn-Fuchs I, Carlens S, Larsson K, Lonnqvist B, Mattsson J, Sparrelid E, Winiarski J, Ringden O. 1998. Results of different strategies for reducing cytomegalovirusassociated mortality in allogeneic stem cell transplant recipients. Transplantation 66:1330-1334

Locatelli F, Percivalle E, Comoli P, Maccario R, Zecca M, Giorgiani G, De Stefano P, Gerna G. 1994. Human cytomegalovirus (HCMV) infection in paediatric patients given allogeneic bone marrow transplantation: Role of early antiviral treatment for HCMV antigenaemia on patients' outcome. Br J Hematol 88:64-71.

Mengelle C, Pasquier C, Rostaing L, Sandres-Saune K, Puel J, Berges L, Righi L, Bouquies C, Izopet J. 2003a. Quantitation of human cytomegalovirus in recipients of solid organ transplants by real-time quantitative PCR and pp65 antigenemia. J Med Virol 69:225-231.

Mengelle C, Sandres-Saune K, Pasquier C, Rostaing L, Mansuy JM, Marty M, Da Silva I, Attal M, Massip P, Izopet J. 2003b. Automated extraction and quantification of human cytomegalovirus DNA in whole blood by real-time PCR assay. J Clin Microbiol 41:38403845 .

Nichols GW, Corey L, Gooley T, Drew WL, Miner R, Huang M-L, Davis C, Boeckh M. 2001. Rising pp65 antigenemia during preemptive anticytomegalovirus therapy after allogeneic hematopoietic stem cell transplantation: Risk factors, correlation with DNA load, and outcomes. Blood 97:867-874.

Paya CV, Wilson JA, Espy MJ, Sia IG, DeBernardi MJ, Smith TF, Patel R, Jenkins G, Harmsen WS, Vanness DJ, Wiesner RH. 2002. Preemptive use of oral ganciclovir to prevent cytomegalovirus infection in liver transplant patients: A randomized placebocontrolled trial. J Infect Dis 185:854-860.

Razonable RR, Brown RA, Wilson J, Groettum C, Kremers W, Espy M, Smith TF, Paya CV. 2002a. The clinical use of various blood compartments for cytomegalovirus (CMV) DNA quantitation in transplant patients with CMV disease. Transplantation 73:968973. 
Razonable RR, Paya CV, Smith TF. 2002b. Role of the laboratory in the diagnosis and management of cytomegalovirus infection in hematopoietic stem cell and solid-organ transplant recipients. J Clin Microbiol 40:746-752.

Revello MG, Zavattoni M, Percivalle E, Grossi P, Gerna G. 1989. Correlation between immunofluorescent detection of human cyto megalovirus immediate early antigens in polymorphonuclear leukocytes and viremia. J Infect Dis 160:159-160.

Van der Bij W, Schirm J, Torensma R, Van Son WJ, Tegzess AM, The TH. 1988. Comparison between viremia and antigenemia for detection of cytomegalovirus in blood. J Clin Microbiol 26:25312535. 